\title{
Changes in Free Amino Acid Content in 'Jonagold' Apple Fruit as Related to Branched-chain Ester Production, Ripening, and Senescence
}

\author{
Nobuko Sugimoto \\ Department of Horticulture, Michigan State University, East Lansing, MI 48824
}

\author{
A. Daniel Jones \\ Department of Biochemistry and Molecular Biology and Department of Chemistry, Michigan State \\ University, East Lansing, MI 48824 \\ Randolph Beaudry ${ }^{1}$ \\ Department of Horticulture, Michigan State University, A22 Plant and Soil Science Building, East \\ Lansing, MI 48824
}

\begin{abstract}
ADDITIONAL INDEX WORDS. aroma, metabolism, liquid chromatography, branched-chain aminotransferase, pyruvate decarboxylase, threonine deaminase, Malus $\times$ domestica

Aвstract. The relationship among the free amino acid content, the expression of genes related to branched-chain amino acid metabolism \{branched-chain aminotransferase [BCAT], $\alpha$-keto acid decarboxylase [pyruvate decarboxylase (PDC)], and threonine deaminase $[\mathrm{TD}]\}$, and the production of branched-chain (BC) esters during ripening and senescence in 'Jonagold' apple fruit (Malus $\times$ domestica) was studied. Eighteen amino acids were measured by liquid chromatography coupled with tandem mass spectrometry. The content for all amino acids changed with developmental stage and some shared similar patterns of accumulation/diminution. The pattern for isoleucine differed from all other amino acids, increasing more than $\mathbf{2 0}$-fold during the ripening process. The onset of the increase was concomitant with the onset of increasing ethylene and $\mathrm{BC}$ ester production and the content remained elevated even during senescence. The elevated isoleucine levels are consistent with an increase in the flux through the pathway leading to the formation and degradation of the isoleucine precursor $\alpha$-keto- $\beta$-methylvalerate, which is used for production of $\mathrm{BC}$ esters containing 2-methylbutanol and 2-methylbutanoate moieties. Unexpectedly, the content of threonine, the amino acid from which isoleucine is thought to be derived in plants, did not change in concert with isoleucine, but rather declined somewhat after ripening was well underway. Patterns in the expression of some, but not all, of the putative BCAT and PDC genes appeared to reflect the rise and fall in ester formation; however, the expression of putative TD genes did not change during ripening. The patterns in gene expression and amino acid content are interpreted to suggest that the synthesis of $\alpha$-keto- $\beta$-methylvalerate and isoleucine during apple ripening may depend on an as yet uncharacterized pathway that bypasses threonine, similar to the citramalate pathway found in some bacteria.
\end{abstract}

Esters are the primary aroma impact compounds produced in ripening apple fruit and normally account for $80 \%$ to $95 \%$ of the total volatiles emitted (Paillard, 1990). Fresh apples autonomously produce an abundance of hexyl acetate, butyl acetate, and 2methylbutyl acetate, which confer typical apple aroma characteristics (Paillard, 1990). The esters are largely composed of either straight- or branched-chain alkyl (alcohol-derived) and alkanoate (acid-derived) groups. The ester product is formed from the condensation of an alcohol and a Co-A derivative of a carboxylic acid by alcohol acyltransferase (AAT) (Ueda and Ogata, 1977). Ester precursors are suggested to be produced primarily by degradative processes. Straight-chain ester precursors have been proposed to form from fatty acid degradation through $\beta$-oxidation or the lipoxygenase system (Sanz et al., 1997) and BC ester precursors have been proposed to be derived from branched-chain amino acid (BCAA) degradation (Gonda et al., 2010; Rowan et al., 1996; Tressl and Drawert, 1973; Wyllie and Fellman, 2000).

The BC $\alpha$-keto acids, $\alpha$-keto- $\beta$-methylvalerate, $\alpha$-ketoisovalerate, and $\alpha$-ketoisocaproate are substrates for the

Received for publication 14 Apr. 2011. Accepted for publication 7 Sept. 2011. ${ }^{1}$ Corresponding author. E-mail: beaudry@msu.edu. synthesis of the three BCAAs, isoleucine, valine, and leucine, respectively. The reaction is catalyzed by one or more BCAT proteins (Fig. 1). This reversible reaction is also the first step in BCAA degradation. Feeding studies have demonstrated that labeled leucine yields 3-methylbutanol and 3-methylbutanoate and their respective esters, valine metabolism produces 2-methylpropanol and 2-methylpropanoate and their respective esters, and isoleucine yields 2-methylbutanol and 2-methylbutanoate and their respective esters (Pérez et al., 2002; Rowan et al., 1996, 1998; Tressl and Drawert, 1973; Wyllie and Fellman, 2000; Wyllie et al., 1996). The BC $\alpha$-keto acids are in approximate equilibrium with their respective BCAAs (Tewari et al., 2000), so it is expected that the pools of BCAAs roughly mirror the pools of their respective $\mathrm{BC} \alpha$-keto acids. Because the $\mathrm{BC} \alpha$-keto acids, not the BCAAs, serve as direct substrates for the reactions leading to the formation of alkyl and alkanoate $\mathrm{BC}$ precursors to $\mathrm{BC}$ esters, it might be more correctly stated that $\mathrm{BC}$ $\alpha$-keto acids, rather than BCAAs, are most immediately related to ester precursor formation. In fact, $\mathrm{BC}$ esters can be produced directly from exogenously supplied BC $\alpha$-keto acids (Gonda et al., 2010), which suggests that the BC esters can be formed without participation of the BCAAs. To some extent, therefore, 


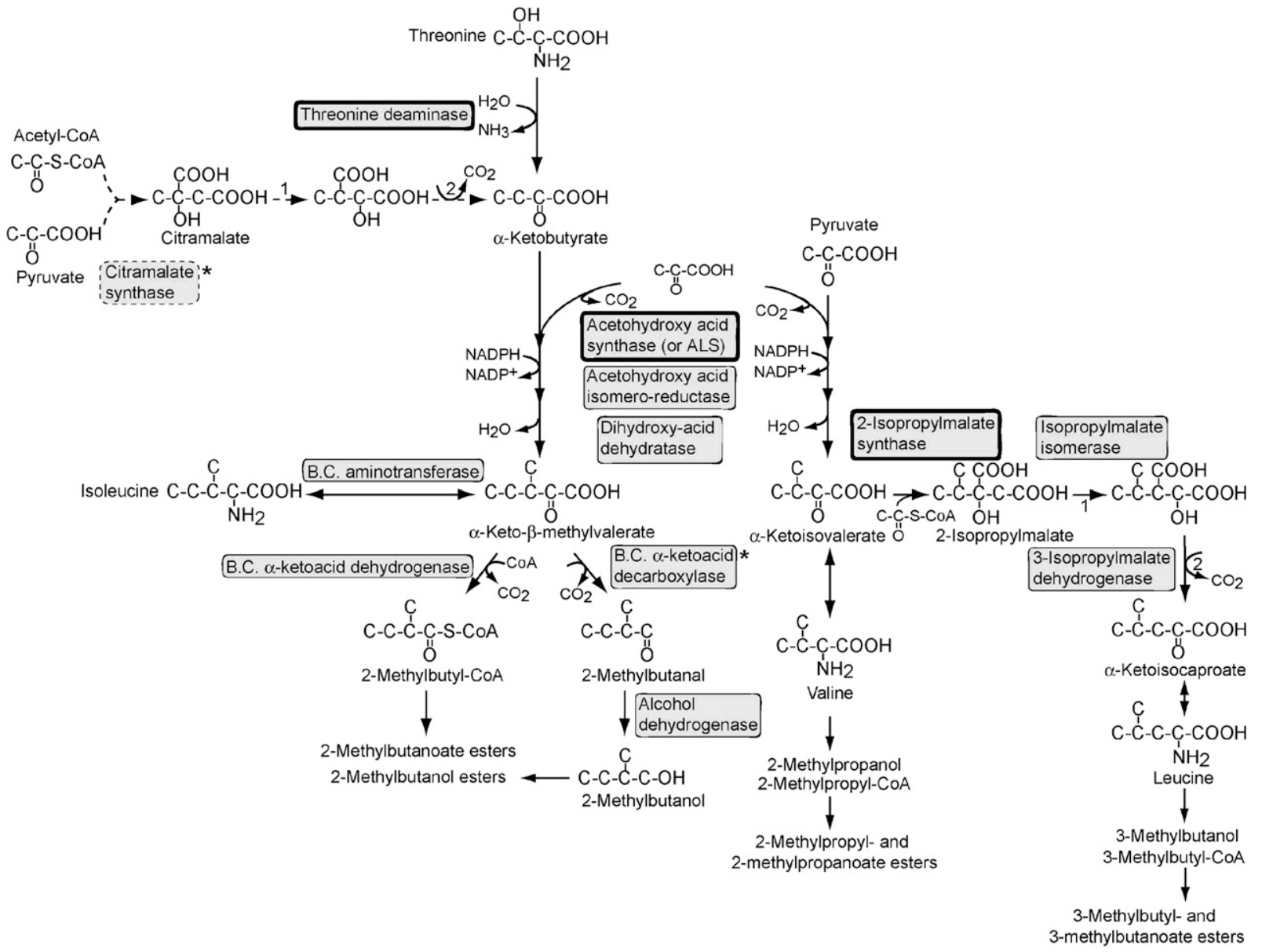

Fig. 1. Putative (dashed lines) and demonstrated (solid lines) pathways involved in branched-chain ester biosynthesis. Genes in bold indicate that they are regulated by feedback inhibition, threonine deaminase is inhibited by isoleucine, but stimulated by valine, acetohydroxy acid synthase [also known as acetolactate synthase (ALS)] is inhibited by valine and leucine and 2-isopropylmalate synthase is inhibited by leucine. *The gene is found in bacteria but not in plants. Hydrogens in carbon-hydrogen bonds are not shown. Numbers 1 and 2 in the putative pathway are considered to share the same enzyme in the leucine biosynthesis isopropylmalate isomerase and 3-isopropylmalate dehydrogenase, respectively.

in apple fruit, 2-methylbutyl- and 2-methylbutanoate esters can be thought to result from enhanced catabolism of $\alpha$-keto- $\beta$ methylvalerate, the precursor to isoleucine, rather than isoleucine per se.

In apples, esters originating from $\alpha$-keto- $\beta$-methylvalerate (isoleucine precursor) predominate and those from $\alpha$-ketoisovalerate (valine precursor) can be detected occasionally at low levels (Ferenczi, 2003; Mattheis et al., 1998; Ortiz et al., 2010; Plotto et al., 2000; Sugimoto, 2007). Although a small amount of leucine is found in ripening apple fruit (Burroughs, 1970; Hansen, 1970), there are few esters produced from $\alpha$-ketoisocaproate (leucine precursor). During apple fruit ripening, isoleucine has been reported to accumulate, but not the other BCAAs (Defilippi et al., 2005; Nie et al., 2005). The increase in isoleucine is accompanied by an increase in its respective $\mathrm{BC}$ esters, $\mathrm{BC}$ alcohols, and $\mathrm{BC}$ aldehydes (Nie et al., 2005; Pérez et al., 2002; Tressl and Drawert, 1973).

The interconversion of $\alpha$-keto- $\beta$-methylvalerate to the alcohol required for 2-methylbutyl esters is through two enzymatic steps. The first involves its decarboxylation by $\mathrm{BC}$ $\alpha$-ketoacid decarboxylase (BC 2-ketoacid decarboxylase or PDC) to 2-methylbutanal. In the second step, 2-methylbutanal is acted on by alcohol dehydrogenase to form 2-methylbutanol (Wyllie et al., 1996). The conversion of $\alpha$-keto- $\beta$-methylvalerate to acids required for 2-methylbutanoate esters is through dehydrogenation by branched-chain $\alpha$-ketoacid dehydrogenase to 2-methylbutyl-CoA. The dehydrogenase pathway is considered as a major route for BCAA catabolism in most organisms, whereas the PDC pathway has been extensively studied only in yeast and bacteria (Dickinson et al., 1997, 1998, 2000; Smit et al., 2004).

In the final enzymatic step of the BC ester biosynthetic pathway, AAT combines 2-methylbutyl-CoA and/or 2-methylbutanol with various alcohols and acyl-CoAs, respectively, to create a wide variety of esters. The substrate specificity of AAT is believed to markedly impact the ester profile (Aharoni et al., 2000; Olías et al., 2002; Souleyre et al., 2005; Ueda et al., 1992; Yahyaoui et al., 2002). However, the AAT of apple cannot discriminate between 2-methylbutyl and 3-methylbutyl precursors (Wyllie et al., 1996). The predominance of 2-methylbutyl and lack of 3-methylbutyl esters in apple therefore suggests that precursor formation and availability is critical for $\mathrm{BC}$ ester biosynthesis. It is generally accepted that AAT will influence the ester profile, but control of ester synthesis probably lies at the level of ester precursor formation (Ferenczi et al., 2006; Wyllie and Fellman, 2000).

Isoleucine is synthesized from threonine through aspartate in plants. Aspartate originates from the tricarboxylic acid (TCA) cycle and is used to synthesize several amino acids including lysine, methionine, and threonine (Azevedo et al., 1997). To 
synthesize isoleucine, threonine is deaminated to $\alpha$-ketobutyrate by TD (Binder, 2010) (Fig. 1). The isoleucine precursor, $\alpha$-keto$\beta$-methylvalerate, is synthesized from $\alpha$-ketobutyrate by three enzymes: acetohydroxy acid synthase [also known as acetolactate synthase (ALS)], acetohydroxy acid isomero-reductase, and dihydroxy-acid dehydratase acting in succession. These enzymes also catalyze the formation of $\alpha$-ketoisovalerate from pyruvate to synthesize valine. Leucine synthesis, however, begins with the valine precursor, $\alpha$-ketoisovalerate, which is acted on by three enzymes, 2-isopropylmalate synthase (IPMS), isopropylmalate isomerase, and 3-isopropylmalate dehydrogenase, to form $\alpha$-ketoisocaproate.

Biosynthesis of all three BCAAs is responsive to feedback regulation. TD is inhibited by isoleucine but stimulated by valine, ALS is inhibited by valine and leucine, and IPMS is inhibited by leucine (Eisenstein, 1991; Singh and Shaner, 1995; Wessel et al., 2000). The accumulation of isoleucine in some ripening apple fruit (Nie et al., 2005) is not consistent with its known regulation by feedback inhibition.

To our knowledge, detailed information about the concentration of the free amino acids in apple throughout ripening and senescence is not available. The objective of this work was to examine the relationship among the free amino acid content, the expression of genes related to BCAA metabolism, and the production of $\mathrm{BC}$ esters during apple fruit ripening.

\section{Materials and Methods}

Plant material. 'Jonagold' apples were harvested for examination every 3 to $4 \mathrm{~d}$ from research plots at the Michigan State University Clarksville Horticultural Experiment Station in Clarksville from 2 Sept. 2004 (Day 0) until ripening was fully engaged on 7 Oct. 2004 (Day 35). On each occasion, fruit were held overnight in the laboratory to equilibrate to laboratory temperature $\left(20 \pm 1{ }^{\circ} \mathrm{C}\right)$ and covered with ventilated, black, 0.1-mm-thick plastic bags to avoid desiccation and responses to intermittent laboratory light before analysis. All fruit $(\approx 200)$ remaining on the trees were harvested and transported to the laboratory on 7 Oct. 2004 (Day 35) after it was apparent that ripening was underway. This was done to avoid damage in the field resulting from freezing and fruit drop. Thereafter, these fruit were maintained at room temperature $\left(20 \pm 1{ }^{\circ} \mathrm{C}\right)$, covered with plastic bags to minimize moisture loss as described previously, and subsequently examined every 3 to $4 \mathrm{~d}$ until the conclusion of the study on 23 Nov. 2004 (Day 81).

On each evaluation date, 20 apples were randomly chosen and the internal ethylene content of each was measured as described subsequently. Of these, 14 fruit having an internal ethylene content nearest the median were selected for further analysis. The four fruit having ethylene levels closest to the median were used for analysis of $\mathrm{CO}_{2}$ production and ester emission. Maturity analysis [percent red coloration, background color, soluble solids concentration $(\%)$, and starch index] was performed on the remaining 10 fruit on each date as described by Mir et al. (2001). From these fruit, the skin and 2 to $3 \mathrm{~mm}$ of underlying cortex tissue were removed and immediately frozen in liquid nitrogen and stored at $-80{ }^{\circ} \mathrm{C}$. Two replicates were created, each consisting of pooled tissue samples from five fruit. Pooled tissue samples were used for amino acid and gene expression studies.

Measurement of internal ETHyLene. The internal ethylene content of apple fruit was determined by withdrawing a 1-mL gas sample from the interior of the apples and subjecting the gas sample to gas chromatography (GC) analysis (Carle Series 400 AGC; Hach Co., Loveland, CO) as previously described (Mir et al., 2001). The GC was fitted with a 6-m-long, 2-mm i.d. stainless-steel column packed with activated alumina and was equipped with a flame ionization detector. The ethylene detection limit was $\approx 0.005 \mu \mathrm{L} \cdot \mathrm{L}^{-1}$. Ethylene concentrations were calculated relative to the certified standard (Matheson Gas Products, Montgomeryville, PA) containing $0.979 \mu \mathrm{L} \cdot \mathrm{L}^{-1}$ ethylene, $4.85 \% \mathrm{CO}_{2}$, and $1.95 \% \mathrm{O}_{2}$ balanced with $\mathrm{N}_{2}$.

Measurement of ReSPiration. Respiration was sampled at the same time volatiles were measured. Apples were each placed into 1-L Teflon chambers (Savillex, Minnetonka, MN) and held for $20 \mathrm{~min}$ at $20{ }^{\circ} \mathrm{C}$. $\mathrm{CO}_{2}$ accumulation was measured by withdrawing $0.1-\mathrm{mL}$ gas samples from a sampling port in the lid of the chamber, which was sealed with a Teflon-lined half-hole septum (Supelco, Bellefonte, PA) using an insulin-type plastic syringe. The gas sample was injected into an infrared gas analyzer (Model 225-MK3; Analytical Development Co., Hoddesdon, U.K.) operated in a flow-through mode with $\mathrm{N}_{2}$ as the carrier gas and a flow rate of $100 \mathrm{~mL} \cdot \mathrm{min}^{-1}$. The $\mathrm{CO}_{2}$ concentration was calculated relative to the certified standard noted previously.

Volatile analysis. Ester, alcohol, and aldehyde measurement was by GC coupled with time-of-flight mass spectrometry (TOFMS). Headspace volatiles were sampled using a $1-\mathrm{cm}$ long, solid-phase microextraction (SPME) fiber ( $65 \mu \mathrm{m}$ PDMSDVB; Supelco). After a 3-min sorption time, the SPME fiber was immediately transferred to a GC (HP-6890; HewlettPackard, Wilmington, DE) splitless injection port at $230^{\circ} \mathrm{C}$ and desorbed for $2 \mathrm{~min}$. The GC was equipped with a mass selective detector (Pegasus II; LECO, St. Joseph, MI). Conditions of GC separation and TOFMS analysis were as previously described (Song et al., 1997). Identification of compounds was by comparison of the mass spectrum with authenticated reference standards and/or with spectra in the National Institute for Standard and Technology mass spectrum library (Version 05). Volatile compounds were quantified by calibrating with a known amount of an authenticated, high-purity standard mixture of 20 volatilized alcohols, aldehydes, and esters as previously described (Song et al., 1997). Where no standard was available, volatiles were quantified by estimation of the instrument response factor based on the Kovats index for the compound of interest (Bartelt, 1997). There were four replicate samples on each analysis date.

Isolation of RNA. Eight developmental stages were selected for analysis of expressed genes based on physiological changes during ripening (Fig. 2). These stages are: Stage 1 (Day 0 ), early climacteric; Stage 2 (Day 11), late preclimacteric and onset of trace ester biosynthesis; Stage 3 (Day 25), onset of autocatalytic ethylene and rapid increase of ester biosynthesis; Stage 4 (Day 32), half-maximal ester biosynthesis and engagement of the respiratory climacteric; Stage 5 (Day 39), near maximal ester biosynthesis, peak in respiratory activity, and onset of rapid tissue softening; Stage 6 (Day 49), end of maximal ester biosynthesis, conclusion of the respiratory climacteric, and completion of tissue softening; Stage 7 (Day 60), midpoint in the decline in ester biosynthesis, maximal ethylene production, and onset of senescence; and Stage 8 (Day 70), postclimacteric minimum in ester production and extensive fruit senescence.

Approximately $5 \mathrm{~g}$ of 'Jonagold' apple skin and 2 to $3 \mathrm{~mm}$ of underlying cortex tissue was used to isolate total RNA by hot borate/phenol extraction followed by $\mathrm{LiCl}$ precipitation (López-Gómez and Gómez-Lim, 1992). 
Semiquantitative ReVERSE TRANSCRIPTION-POLYMERASE CHAIN REACTION ANALYSIS. The expression of 10 BCAT, six PDC, and two TD genes, and the $18 \mathrm{~S}$ ribosomal RNA (18s rRNA)

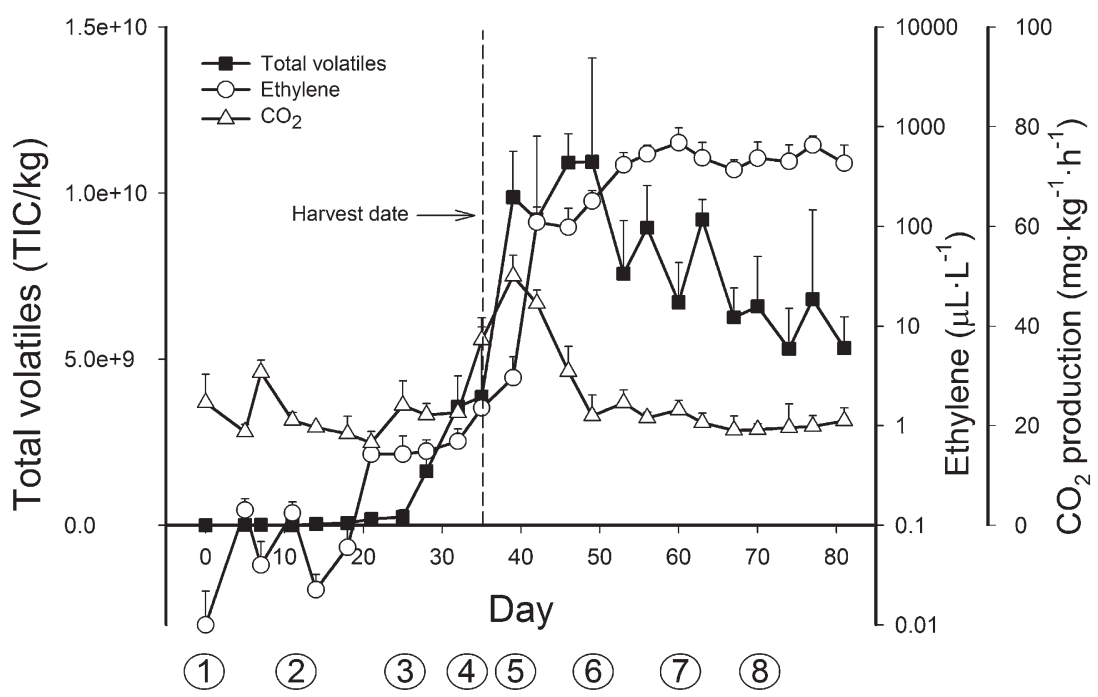

Fig. 2. Internal ethylene, total volatiles [in total ion count (TIC)] and $\mathrm{CO}_{2}$ production in pre-climacteric through post-climacteric 'Jonagold' apples. Fruit were examined from 2 Sept. 2004 (Day 0) to 23 Nov. 2004 (Day 81). Fruit were collected from the field until 7 Oct. 2004 (Day 35) and thereafter maintained at room temperature $\left(21 \pm 1^{\circ} \mathrm{C}\right)$. Each symbol represents the average of four replications. Vertical bars represent mean \pm SD. Eight time points (Days 0, 11, 25, 32, 39, 49, 60, 70) were selected for amino acid and gene expression analyses based on distinct physiological stages. gene (Table 1) was measured using semiquantitative polymerase chain reaction (PCR) analysis. Contigs of BCAT, PDC, and TD were assembled using all available expressed sequence tags (ESTs) in the non-redundant nucleotide database of the National Center for Biotechnology Information (NCBI). The methods used to identify ESTs for the creation of contigs and contig assembly and annotation were as described in Park et al. (2006). With the exception of BCAT3, PCR primers were contained within a single EST used for assembling contigs. For BCAT3, the forward primer spans two ESTs, CO541320 and CO899974. The BCAT10 clone (CO868030) was donated by S.S. Korban (University of Illinois, UrbanaChampaign) and was re-sequenced from the 3' end at the Genomics Technology Support Facility (GTSF) of the Genomics Core in Michigan State University, East Lansing. The PDC1 clone (CK900568) was re-sequenced from the $3^{\prime}$ end at GTSF. The resulting sequences were used to generate primers for PCR analysis.

For each PCR analysis, two biological replicates were used with the exception of $T D$ for which only one replicate was analyzed. cDNA synthesis and PCR reactions were performed using commercially available kits

Table 1. Putative branched-chain aminotransferase (BCAT), pyruvate decarboxylase $(P D C)$, threonine deaminase (TD) genes and the $18 \mathrm{~S}$ ribosomal RNA (18s rRNA) gene with accession number, GenBank number, forward and reverse primer sequence $\left(5^{\prime} \rightarrow 3^{\prime}\right)$, and expected polymerase chain reaction gene fragment size (bp) for semiquantitative reverse transcription-polymerase chain reaction. ${ }^{\mathrm{z}}$

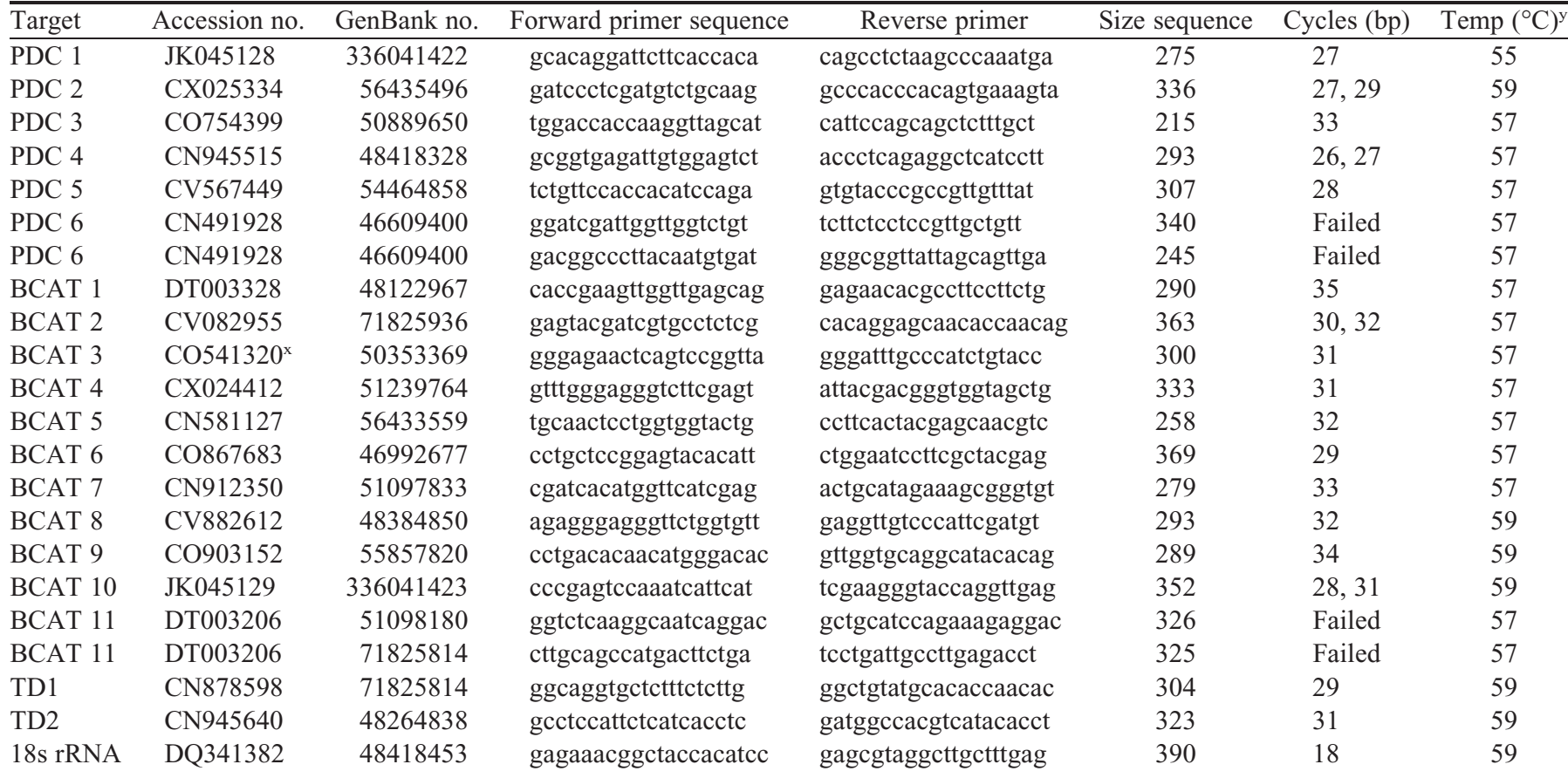

${ }^{\mathrm{z}}$ With the exception of BCAT3, accession numbers represent one of the ESTs used in the assembly of contigs that contained the region between the forward and reverse primers. Genes are included for which PCR was not successful. A single number in "cycles" indicates that the same cycle was performed with biological replications 1 and 2. Two numbers indicate that different cycles were performed between biological replications for optimum result.

${ }^{y}$ Annealing temperature.

${ }^{x}$ Forward primer spans two ESTs, CO541320 and CO899974.

ESTs = expressed sequence tags; PCR = polymerase chain reaction. 
according to manufacturer (Invitrogen, Carlsbad, CA) directions. Before creating cDNA, total RNA was treated with DNase using an RNase-free DNase kit according to the manufacturer (Qiagen, Valencia, CA). One microgram of DNase-treated total RNA was reverse transcribed using oligo (dT)12-18 primer or random hexamer and SuperScript II as described by the manufacturer (Invitrogen). cDNA created with oligo (dT)12-18 primer was used for $18 \mathrm{~s}$ rRNA, BCAT and $P D C$ expression and cDNA created with random hexamer were used for $T D$ expression analysis. cDNAs $(1.0 \mu \mathrm{L})$ were used as templates in a $50-\mu \mathrm{L}$ PCR reaction containing $10 \mu \mathrm{M}$ of the forward and reverse genespecific primers. PCR primers were designed using Primer3 (Rozen and Skaletsky, 1999). Primer sequences, the expected size of the PCR product, optimum cycle number, and optimum temperature for primer binding are listed (Table 1). The PCR reaction was performed as follows: 1) $5 \mathrm{~min}$ at $95{ }^{\circ} \mathrm{C}$; 2) $30 \mathrm{~s}$ at $95^{\circ} \mathrm{C}$; 3) 30 s at 55 to $59^{\circ} \mathrm{C}$; 4) $30 \mathrm{~s}$ at $72^{\circ} \mathrm{C}$, repeating 18 to 35 cycles from Steps 2 to 4 ; and 5) final elongation 5 min at $72{ }^{\circ} \mathrm{C}$. The amplified PCR products were separated by electrophoresis on a $1.5 \%(\mathrm{w} / \mathrm{v})$ agarose gel, visualized with ultraviolet fluorescence of ethidium bromide, and photographed. Relative light density of the bands was quantified by a digital imaging system (EagleEye II; Stratagene, La Jolla, CA). To identify the optimum cycle, the gene products amplified by PCR had to be visible on the gel electrophoresis and be quantifiable by light density measurement without saturation of pixels. The number of PCR cycles needed ranged from 26 to 35 (Table 1). A single number indicates that the same cycle was performed with both biological replications. Two numbers indicate that different number cycles were performed for each replicate. PCR reactions for two PDC genes and one BCAT gene were unsuccessful. No products were evident for PDC6 and BCAT11 after two trials using different primers and PDC7 was too short to design appropriate primers.

PCR products were cleaned using a PCR purification kit (QIAquick; Qiagen) and sequenced at GTSF to verify identity. All the PCR-generated sequences were $98 \%$ to $100 \%$ identical to apple fruit ESTs as reported in NCBI.

A partial sequence of the 18s rRNA gene (gi:85717895) was used as an internal control for PCR analyses. Expression data for all genes (PDC, BCAT, and TD) were normalized based on the 18s rRNA spot density. The spot density for the $18 \mathrm{~s}$ rRNA varied $\approx \pm 10 \%$ across the eight developmental stages (data not shown). The values for PCR are calculated as the spot density relative to the maximum value obtained for each gene.

Amino ACID EXtraction. The same eight developmental stages that were selected for gene expression analysis as described previously were used for amino acid analysis (Fig. 2). Two biological replicates were created within the same stage as previously described.

Approximately $5 \mathrm{~g}$ of the frozen apple tissue was ground into fine powder using a liquid $\mathrm{N}_{2}$-cooled mortal and pestle. The ground tissue was further divided into three technical replicates, each containing $0.5 \mathrm{~g}$ of to $6.0 \mathrm{~min}$ ). tissue. The powdered tissue was transferred into $1 \mathrm{~mL}$ of preheated water containing $10 \mu \mathrm{M}$ deuterated methionine (Met$d_{3}$ ) (Cambridge Isotope Laboratories, Andover, MA) as an internal standard, mixed vigorously, and incubated at 90 to $95^{\circ} \mathrm{C}$ for $10 \mathrm{~min}$. After centrifugation at $5000 \mathrm{~g}_{\mathrm{n}}$ for $5 \mathrm{~min}$, the supernatant was filtered through a $0.45-\mu \mathrm{m}$ filter (Millex HA; Millipore, Billerica, MA). The cleared filtrate was diluted into one-fifth of its original concentration with water containing the internal standard and used for analysis.

Amino aCid analysis. The 20 amino acids (Sigma-Aldrich, St. Louis, MO) listed in Table 2 were dissolved in water containing $10 \mu \mathrm{M}$ Met- $d_{3}$ to make individual stock solutions of $1 \mathrm{mM}$. A master mixture was created by mixing all 20 amino acids to a final concentration of $50 \mu \mathrm{M}$ each. A series of six working standards ranging from 0.5 to $40 \mu \mathrm{M}$, each containing $10 \mu \mathrm{M}$ Met- $d_{3}$, was prepared by serial dilutions from the $50 \mu \mathrm{M}$ master mixture using water containing the internal standard. Amino acid samples were quantified by calibration curves obtained from six working standards using linear regression plotting amino acid concentration as a function of ratio of the amino acid peak area to the Met- $d_{3}$ peak area.

Amino acids were analyzed using a tandem mass spectrometer (Quattro micro; Waters, Milford, MA) coupled to a highpressure liquid chromatograph (LC-20AD HPLC; Shimadzu, Columbia, MD) equipped with an autosampler (SIL-5000; Shimadzu). The $2.1 \times 100-\mathrm{mm}$ column was packed with a 3.5- $\mu \mathrm{m}$-diameter C18 stationary phase (Symmetry; Waters) and held isothermally at $30^{\circ} \mathrm{C}$. Injection volume was $10 \mu \mathrm{L}$ and solvents used were $1 \mathrm{mM}$ perfluoroheptanoic acid (mobile Phase A) and acetonitrile (mobile Phase B); the flow rate was held

Table 2. The liquid chromatography coupled with tandem mass spectrometry (MS/MS) conditions for 21 amino acids including deuterated methionine (methionine- $d_{3}$ ) were optimized for $\mathrm{m} / \mathrm{z}$, cone voltage, collision voltage, and retention time. ${ }^{\mathrm{z}}$

\begin{tabular}{|c|c|c|c|c|c|}
\hline Compound & $\begin{array}{c}\text { Mass of parent }> \\
\text { daughter ions }(\mathrm{m} / \mathrm{z})\end{array}$ & $\begin{array}{c}\text { Cone } \\
\text { voltage }(\mathrm{V})\end{array}$ & $\begin{array}{c}\text { Collision } \\
\text { voltage }(\mathrm{V})\end{array}$ & $\begin{array}{l}\text { Retention } \\
\text { time (min) }\end{array}$ & $\begin{array}{c}\text { Function } \\
\text { no. }\end{array}$ \\
\hline Alanine & $89.9>44.0$ & 18 & 15 & 1.53 & 1 \\
\hline Arginine & $175.0>69.9$ & 26 & 20 & 3.91 & 2 \\
\hline Asparagine & $132.9>86.9$ & 26 & 20 & 1.13 & 1 \\
\hline Aspartate & $133.9>73.8$ & 18 & 15 & 1.09 & 1 \\
\hline Cysteine & $122.0>75.9$ & 20 & 15 & 1.28 & 1 \\
\hline Glutamine & $146.9>130.0$ & 18 & 15 & 1.22 & 1 \\
\hline Glutamate & $147.9>83.9$ & 18 & 15 & 1.18 & 1 \\
\hline Glycine & $75.9>30.2$ & 18 & 40 & 1.3 & 1 \\
\hline Histidine & $156.0>110.0$ & 18 & 15 & 3.51 & 2 \\
\hline Isoleucine & $132.0>69.0$ & 18 & 15 & 3.06 & 2 \\
\hline Leucine & $132.0>30.0$ & 18 & 15 & 2.88 & 2 \\
\hline Lysine & $146.9>84.0$ & 18 & 15 & 3.73 & 2 \\
\hline Methionine & $149.9>104.0$ & 18 & 15 & 2.21 & 2 \\
\hline Phenylalanine & $166.0>120.0$ & 18 & 15 & 3.2 & 2 \\
\hline Proline & $116.0>69.9$ & 26 & 15 & 1.51 & 1 \\
\hline Serine & $105.9>59.8$ & 18 & 15 & 1.18 & 1 \\
\hline Threonine & $120.0>56.9$ & 26 & 25 & 1.35 & 1 \\
\hline Tryptophan & $205.0>188.0$ & 18 & 15 & 3.57 & 2 \\
\hline Tyrosine & $182.0>136.1$ & 18 & 15 & 2.19 & 2 \\
\hline Valine & $118.0>71.9$ & 18 & 15 & 2.14 & 2 \\
\hline Methionine- $d_{3}$ & $153.0>107.0$ & 18 & 15 & 2.21 & 2 \\
\hline
\end{tabular}

${ }^{z}$ The parent mass corresponds to amino acid molecular mass plus hydrogen ion and the daughter ion is used for MS/MS, specific $\mathrm{m} / \mathrm{z}$ for selection of the amino acid. The data acquisition was split into two functions, function no. 1 (0 to $1.8 \mathrm{~min})$ and function no. 2 (1.8 
constant at $0.3 \mathrm{~mL} \cdot \mathrm{min}^{-1}$. The gradient program was as follows: $98 \%$ mobile Phase A and 2\% mobile Phase B at start, 20\% mobile Phase $\mathrm{B}$ after $0.1 \mathrm{~min}$, increasing to $40 \%$ mobile Phase B at $2.3 \mathrm{~min}$, and decreasing to $2 \%$ mobile Phase B at 4.1 min for re-equilibration of the column. The total run time was $6 \mathrm{~min}$. Mass spectra were acquired using electrospray ionization in positive ion mode. The capillary voltage was $3.17 \mathrm{kV}$, the extractor voltage was $4 \mathrm{~V}$, the rf lens was held at $0.3 \mathrm{~V}$, the cone gas flow rate was $20 \mathrm{~L} \cdot \mathrm{h}^{-1}$, the desolvation gas flow rate was $400 \mathrm{~L} \cdot \mathrm{h}^{-1}$, the source temperature was $110{ }^{\circ} \mathrm{C}$, and the desolvation temperature was $350{ }^{\circ} \mathrm{C}$ as described in $\mathrm{Gu}$ et al. (2007). The data acquisition method was split into two functions, the first from 0 to $1.8 \mathrm{~min}$ and the second from 1.8 to $6.0 \mathrm{~min}$. Ten multiple reaction monitoring transitions were included in Function 1 and 11 in Function 2. Function number, collision energies, and masses of observed ions for each amino acid are listed in Table 2. Data were collected and quantified with proprietary software (MassLynx 4.0 and QuanLynx; Waters).

\section{Results}

Fruit maturation. Skin color (percent of redness) increased from $22 \%$ on Day 0 to over $95 \%$ by Day 39 (data not shown). Background color (green $=5$, yellow $=1$ ) had a reciprocal pattern relative to red color development, beginning at 5 (green) on Day 0 and gradually decreasing to 1 (yellow) on Day 81 (data not shown). Starch conversion to sugars, as measured by the starch index ( 1 to 8 ) started at 2 on Day 0 and increased linearly with time, reaching a maximum of 8 on Day 32 (data not shown). The pattern for soluble solids was similar to that of starch conversion; the initial soluble solid was $12 \%$ on Day 0 and reached its maximum of $16 \%$ on Day 39 (data not shown). Fruit internal ethylene concentration (IEC) remained low until Day $18\left(0.1 \mu \mathrm{L} \cdot \mathrm{L}^{-1}\right.$ or less) (Fig. 2), after which time IEC rose above $0.2 \mu \mathrm{L} \cdot \mathrm{L}^{-1}$ by Day 21 . The autocatalytic increase in ethylene did not occur until after Day 32 with IEC increasing to over $500 \mu \mathrm{L} \cdot \mathrm{L}^{-1}$ by Day 60 . The respiratory climacteric occurred after Day 32 and appeared to be complete by Day 49.

BRANCHED-CHAIN ESTERS. Esters were first detected at very low levels as early as Day 14, 1 week before ethylene levels greater than $0.2 \mu \mathrm{L} \cdot \mathrm{L}^{-1}$ were sustained. As the ethylene content exceeded $0.2 \mu \mathrm{L} \cdot \mathrm{L}^{-1}$, a rapid and large increase in ester biosynthesis began. Total ester production increased coincident with increased ethylene accumulation in the fruit (Fig. 2). The pattern for BC esters was generally similar to that for total esters, but had a higher, sharper initial peak for 2-methylbutanol esters (Fig. 3A-B). 2-Methylbutanol esters (2-methylbutyl acetate and 2-methylbutyl butanoate) had a lower diversity, but were approximately twice as abundant as 2-methylbutanoate esters (ethyl-, propyl-, butyl-, pentyl-, and hexyl 2-methylbutanoate). The most abundant 2-methylbutanoic acid-derived BC esters were hexyl and butyl 2-methylbutanoate, and the most abundant 2-methylbutanol-derived BC ester was 2-methylbutyl acetate. 2-Methylbutanol and 2-methylbutanal production patterns were similar to those for 2-methylbutanol-derived esters; both peaked on Day 39 and declined rapidly thereafter, then undergoing a slow increase as ripening and senescence continued (Fig. 3C). Free 2-methylbutanoic acid was not detected.

Amino ACIDS. Two amino acids, glycine and cysteine, were not quantifiable because of limitations with the methodology used, but the remaining 18 amino acids were quantified readily. Patterns of change in amino acid content during fruit development were diverse and could be classed as declining, moderately increasing, increasing markedly, declining and then increasing, or increasing and then declining (Fig. 4). Six amino acids, alanine, arginine, aspartate, glutamate, serine, and threonine, decreased relatively steadily throughout ripening, decreasing to $15 \%$ to $20 \%$ of preclimacteric levels. Three amino acids, leucine, tryptophan, and valine, increased moderately (two- to threefold). Asparagine, 

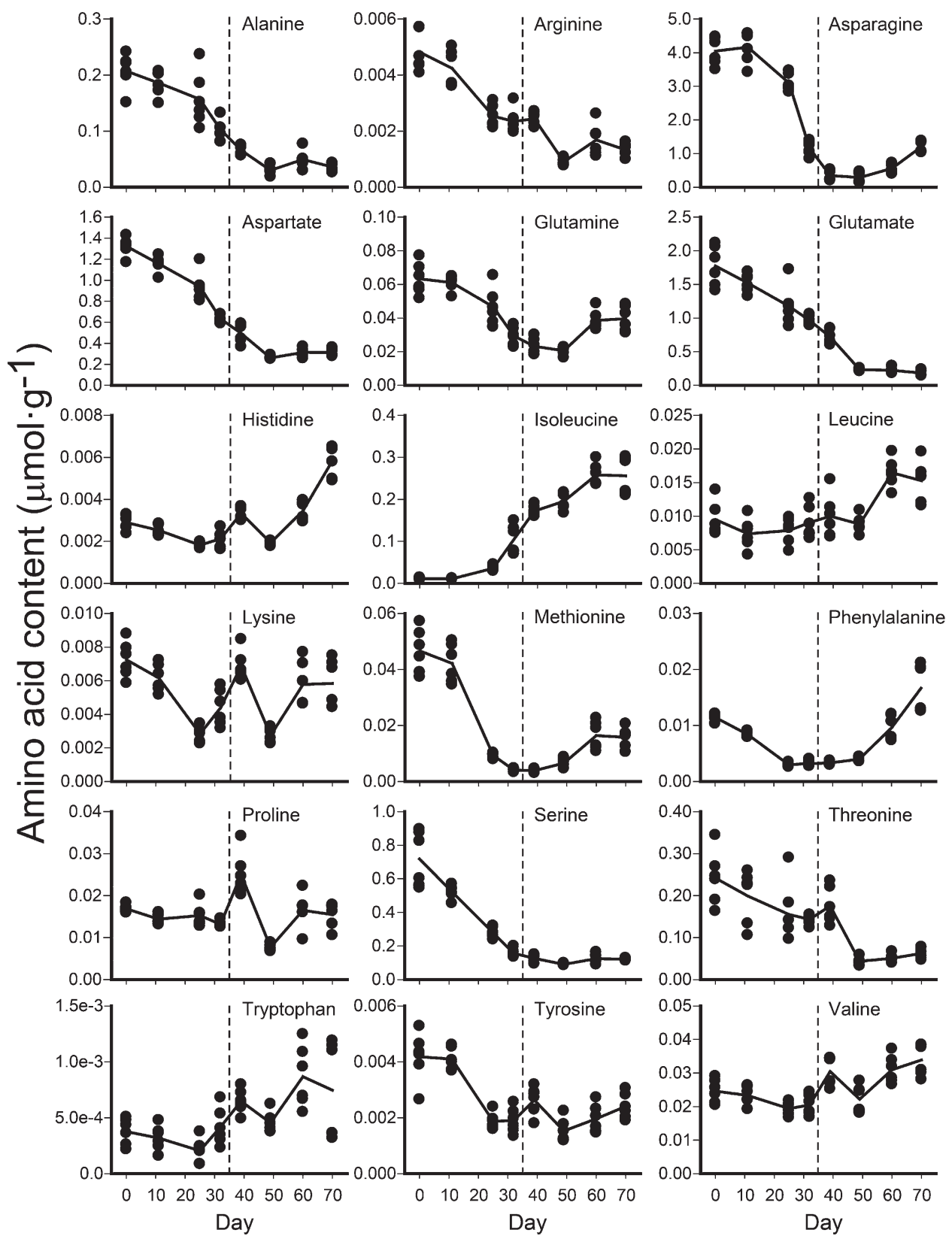

Fig. 4. Ontogeny of amino acid content in pre-climacteric through post-climacteric 'Jonagold' apples. Fruit were examined from 2 Sept. 2004 (Day 0) to 23 Nov. 2004 (Day 81). Fruit were collected from the field until 7 Oct. 2004 (dashed line, Day 35) and thereafter maintained at room temperature $\left(21 \pm 1^{\circ} \mathrm{C}\right)$. Eight time points (Days 0 , $11,25,32,39,49,60,70)$ were selected for amino acid analysis based on distinct physiological stages. There were total of six replications, two biological and three technical replications.

glutamine, phenylalanine, and methionine contents decreased as fruit began to ripen and then gradually increased during the latter phase of senescence. The concentration of histidine, lysine, proline, tyrosine, and tryptophan peaked in concert with the respiratory climacteric. Isoleucine was the only amino acid to increase continuously during ripening with the onset of the increase coincident with the increase in internal ethylene content. The final concentration of isoleucine was more than 20 -fold higher than preclimacteric levels. The compositional change in isoleucine (isoleucine as a percent of total amino acids) shifted almost 85 -fold from $0.13 \%$ to $11 \%$ of total amino acids in unripe to ripe fruit. Isoleucine levels at their peak were 10- and 20 -fold higher than valine and leucine, respectively.
GENE EXPRESSION RELATED TO BRANCHED-CHAIN AMINO ACID METABOLISM. Of the 11 putative BCAT genes, 10 were expressed in the fruit (Table 1). Of these, four (BCAT1, BCAT6, BCAT9, and $B C A T 10)$ had expression patterns peaking on Day 32 then declining thereafter, and one (BCAT2) had an expression pattern that peaked on Day 39 then declined thereafter (Fig. 5A). The remaining five putative BCAT genes (BCAT3, BCAT4, $B C A T 5, B C A T 7$, and BCAT8) had relatively stable expression until approximately Day 25, then declined slightly as ripening and senescence progressed (Fig. 5B). The change in expression of the BCAT genes was not great; increases (relative to initial) were no greater than $40 \%$ and decreases (relative to maximum) were no greater than $80 \%$.

Of the seven putative PDC genes, five were detected as being expressed in the fruit. Expression patterns for the five genes differed, but only one (PDC1) underwent a sustained increase during ripening and senescence (Fig. 6). Of the remaining four, one (PDC4) rapidly increased on Day 32 and declined thereafter, one (PDC5) was stable throughout ripening and slightly increased during senescence, and two (PDC2 and $P D C 3$ ) had their highest expression before the climacteric peak and gradually declined afterward. With the exception of PDC5, most of the PDC genes had a relatively high expression compared with the BCAT genes based on PCR cycle numbers (Table 1).

The two putative TD genes (TD1 and TD2) were expressed in the fruit (Table 1). Unlike BCAT and PDC genes, expression for TD1 and TD2 remained constant during ripening (Fig. 7). Based on the PCR cycles required to obtain an adequate signal, the abundance of $T D 1$ and TD2 transcription products was similar to that for the bulk of the putative BCAT genes.

\section{Discussion}

Maturation. The progression of fruit maturity indices for 'Jonagold' is consistent with those previously published (Beaudry et al., 1993; Schwallier et al., 1995). The onset of ester synthesis with the rise in ethylene is also consistent with the fact that ethylene action is required for the synthesis of ripening-related esters in apple fruit (Defilippi et al., 2005; Ferenczi et al., 2006; Mir et al., 1999; Song and Bangerth, 1996). 


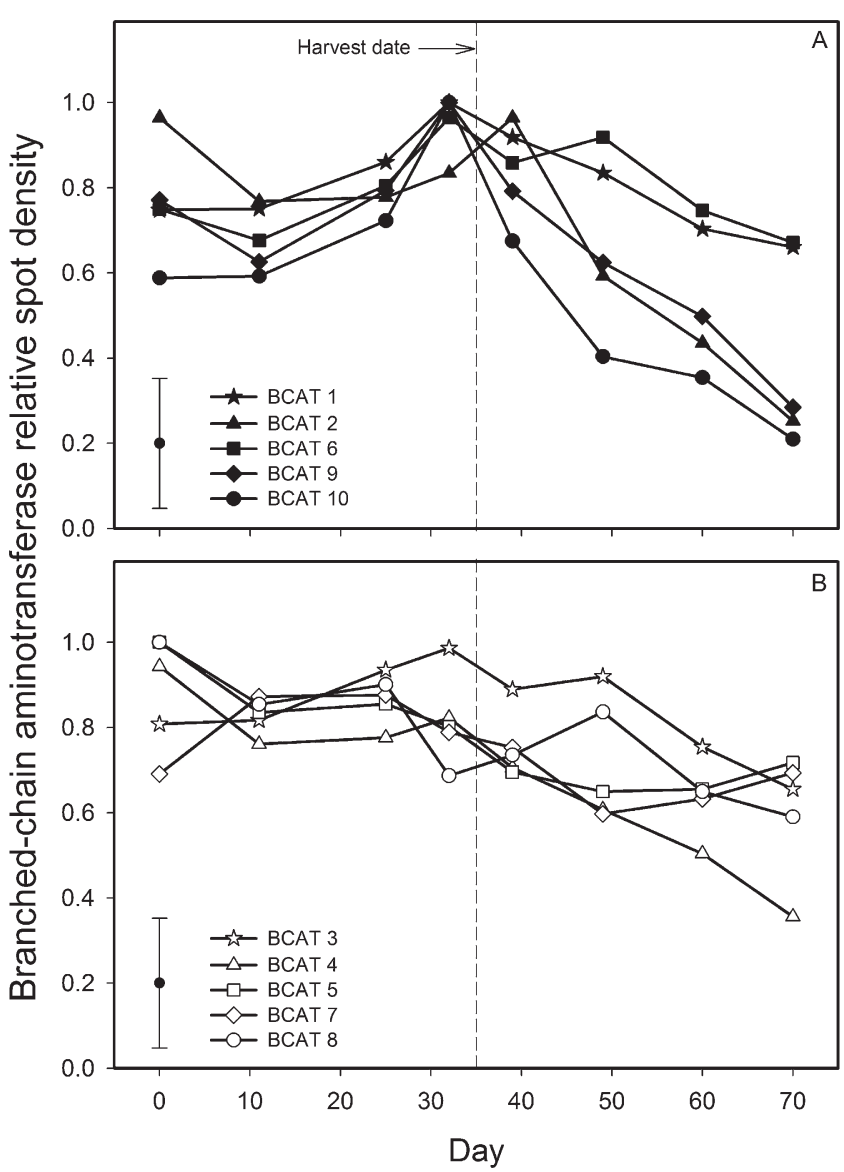

Fig. 5. Expression of putative branched-chain aminotransferase (BCAT) genes for 'Jonagold' apple fruit ripened at room temperature performed by semiquantitative reverse transcription-polymerase chain reaction. The graph's panels A and B were separated by expression pattern purpose only. The values are based on spot density relative to maximum value. $18 \mathrm{~S}$ ribosomal RNA was used as a control. All data are normalized relative to control gene spot density. The control gene spot density ranged between 0.78 and 0.98 . Each symbol represents the average of two replicate measurements. The average pooled SD is 0.15 .

Ester SYNTHESIS. The diversity and quantity of esters that apple fruit produce are cultivar-specific (Dixon and Hewett, 2000; Kakiuchi et al., 1986; Paillard, 1990). With regard to the synthesis of BC esters, some cultivars produce much greater quantities than others. Based on its copious production of 2-methylbutyl and 2methylbutanoate esters, 'Jonagold' can be classified as a BC esterproducing cultivar as are the cultivars Bisbee Delicious (Mattheis et al., 1991a, 1991b), Redchief Delicious (Ferenczi, 2003), Rome (Fellman et al., 1993), and Golden Delicious (Song and Bangerth, 1996). There are cultivars that could be classified as low BC producers such as Annurca (Lo Scalzo et al., 2001). The maintenance of a high rate of production of 2-methylbutyl esters throughout ripening and senescence suggests a consistent production of 2-methylbutanol, which had a pattern of production that reflected that of 2-methylbutyl esters. It may be that high $\mathrm{BC}$ ester-producing lines also produce elevated levels of $\alpha$-keto- $\beta$-methylvalerate, the isoleucine precursor. However, to our knowledge, no analysis has been performed to test this relationship.

Patterns of amino ACID CONTENT AND Gene EXPREssion. Total amino acid content in unripe fruit was similar to that quantified in wild-type 'Columbia' arabidopsis (Arabidopsis

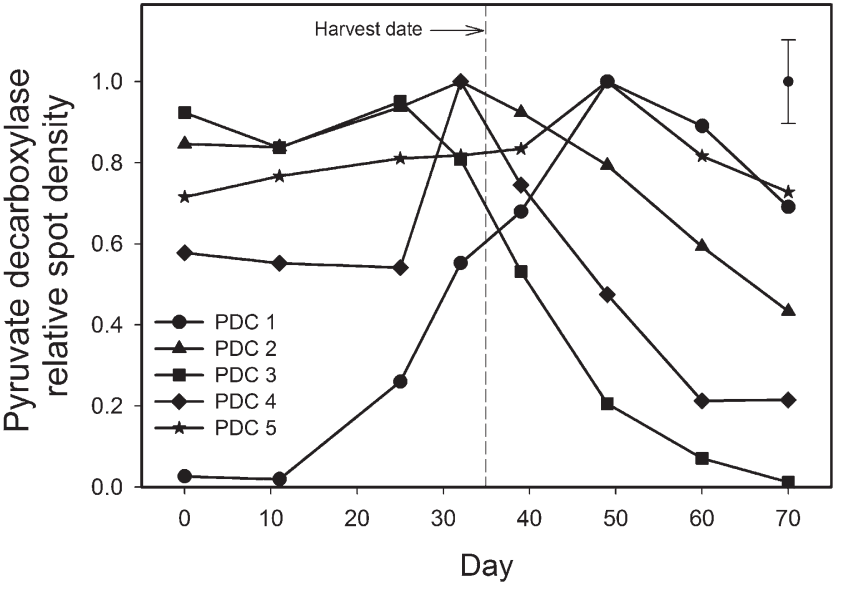

Fig. 6. Expression of putative pyruvate decarboxylase $(P D C)$ genes for 'Jonagold' apple fruit ripened at room temperature performed by semiquantitative reverse transcription-polymerase chain reaction. The values are based on spot density relative to maximum value. $18 \mathrm{~S}$ ribosomal RNA was used as a control. All data are normalized relative to control gene spot density. The control gene spot density ranged between 0.78 and 0.98 . Each symbol represents the average of two replications. The average pooled SD is 0.10 .

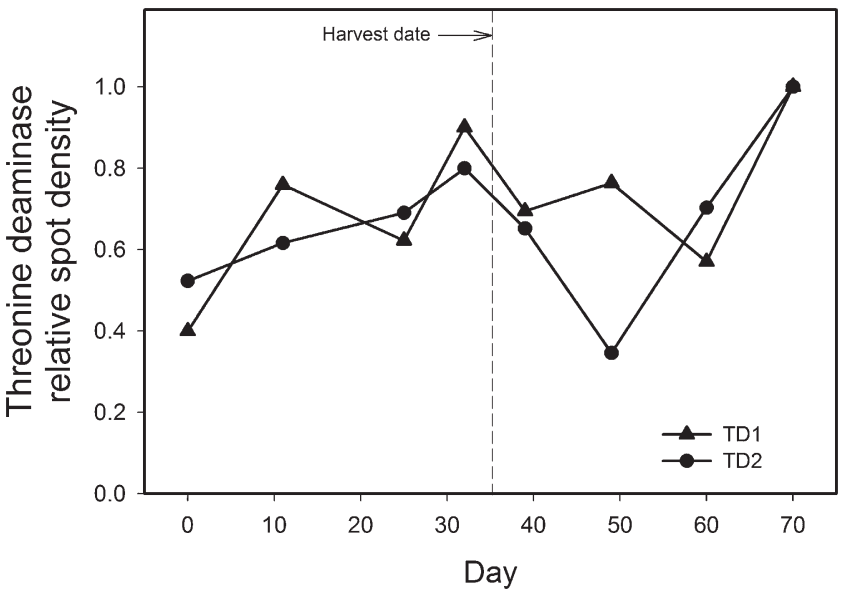

Fig. 7. Expression of putative threonine deaminase (TD) genes for 'Jonagold' apple fruit ripened at room temperature performed by semiquantitative reverse transcription-polymerase chain reaction. The value is based on spot density relative to maximum value. $18 \mathrm{~S}$ ribosomal RNA was used as a control. All data are normalized relative to control gene spot density. The control gene spot density ranged between 0.78 and 0.98 .

thaliana) seeds (Lu et al., 2008). Although the free amino acid content in apple fruit was not directly comparable to previously studies on amino acids in apples (Ackermann et al., 1992; Burroughs, 1957; Defilippi et al., 2005; Nie et al., 2005) as a result of methodological differences, comparison of the fraction of each amino acid was possible. Averaging across developmental stages, asparagine (45\%), aspartate (16\%), glutamate (23\%), and serine $(5 \%)$ were the major amino acids in 'Jonagold' fruit and accounted for more than $80 \%$ of the quantified 18 amino acids. These four amino acids were also found to predominate in the cultivars Court Royal, Morgan Sweet, Reine des Pommes, Kingston Black, Yarlington Milll, and Dabinett (Burroughs, 1957); Collaos, Meana, Picona Rayada, and Raxao (Blanco Gomis et al., 1992); Granny Smith (Magné et al., 1997); and Glockenapfel (Ackermann 
et al., 1992). However, our numbers did not agree with the data from Wu et al. (2007) for a 'Jonagold' juice extract, in which alanine $(25 \%)$ had the highest proportion followed by serine $(6 \%)$, glutamine $(5 \%)$, and asparagine (5\%). However, aspartate and glutamate levels were not reported in this study. Differences in our results may be related to the stage of development when the fruit was examined, the extraction method for free amino acids, or the fact that the data for aspartate and glutamate were not reported in the cited study.

Five amino acids, asparagine, lysine, threonine, methionine, and isoleucine (through threonine), are synthesized from aspartate, which originates from oxaloacetate from the TCA cycle in the mitochondria (Azevedo et al., 1997; Bartlem et al., 2000; Coruzzi and Last, 2000). With the exception of isoleucine, the concomitant decline in aspartate and its products asparagine, lysine, threonine, and methionine is consistent with their linkages with aspartate metabolism. Even so, the lysine pattern was somewhat different from that of the other aspartate-derived amino acids, perhaps because lysine biosynthesis is considered to be strongly regulated by itself without affecting the flux of the aspartate pathway (Azevedo et al., 1997). The increase in isoleucine, despite a decrease in threonine, is difficult to explain. Increasing isoleucine and depletion of threonine could result from an increase in the activity of TD. However, the lack of an increase in $T D$ expression would suggest that simple genetic regulation at this step is not responsible. Protein synthesis remains highly active in ripening fruit (Frenkel et al., 1968), so it seems unlikely that isoleucine would accumulate preferentially as a result of a decline in its incorporation in proteins or enhanced proteolysis. Given that isoleucine inhibits the activity of TD in plants (Mourad and King, 1995), it is not clear how isoleucine was able to accumulate and threonine to decline. Generally, suppression of a step in a metabolic pathway leads to the accumulation of intermediates in earlier steps. For instance, Bartlem et al. (2000) observed that the inhibiting threonine synthesis caused the methionine accumulation in arabidopsis.

Isoleucine and the other BCAAs are products of an aminotransferase reaction in which glutamate acts as a donor to transfer its amino group to BC $\alpha$-keto acids to form the BCAAs and $\alpha$-ketoglutarate (Goto et al., 2003). In this way, glutamate contributes to the synthesis of valine, isoleucine, and leucine from $\alpha$-ketoisovalerate, $\alpha$-keto- $\beta$-methylvalerate, and $\alpha$-ketoisocaproate, respectively. Our data show that glutamate decreases as 'Jonagold' fruit ripen. However, the decrease in glutamate was not reflected by declines in any of the three BCAAs, suggesting that glutamate was likely not limiting to the aminotransferase reactions. That being said, it can be deduced that glutamate levels did not promote transferase reactions. In fact, according to Tewari et al. (2000), the formation of the BC $\alpha$-keto acid is energetically favored over the BCAA in the BCAT reaction. Similarly, Gonda et al. (2010) found that CmBCAT1 from melon (Cucumis melo) converted isoleucine and leucine to $\alpha$-keto- $\beta$-methylvalerate and a-ketoisovalerate, respectively, and vice versa, indicating that the enzyme carries out a freely reversible reaction. Therefore, to explain the accumulation of isoleucine, the decline in glutamate would have to be balanced by a significant increase in the content of $\alpha$-keto- $\beta$-methylvalerate or a marked decline in $\alpha$-ketoglutarate. To our knowledge, changes in the levels of these metabolites during apple fruit ripening have not been determined. However, Aharoni et al. (2002) determined that $\alpha$-ketoglutarate declined severalfold during fruit ripening in strawberry (Fragaria $\times$ ananassa).
The greater than 20-fold increase in isoleucine content found in this study was similar to that found in 'Greensleeves' apples, which experience a more than 10 -fold increase in isoleucine during ripening (Defilippi et al., 2005). Nie et al. (2005) also observed the increase in isoleucine during apple ripening in 'Starkrimson'. The data from our study and these two previous studies indicate that biosynthesis of isoleucine outpaces its catabolism.

Because 2-methylbutyl BC esters in apple appear to be formed from the dehydrogenation and decarboxylation of $\alpha$-keto$\beta$-methylvalerate (Gonda et al., 2010), 2-methylbutyl BC esters may be considered a byproduct of $\alpha$-keto- $\beta$-methylvalerate metabolism. Viewing BC ester formation in apple as a function of $\mathrm{BC} \alpha$-keto acid synthesis, rather than BCAA degradation, runs counter to the way $\mathrm{BC}$ ester formation is often described. Investigators have suggested that isoleucine is converted into $\alpha$-keto$\beta$-methylvalerate through BCAT, thereby facilitating BC ester formation (Gonda et al., 2010; Pérez et al., 2002; Rowan et al., 1996). However, as noted previously, isoleucine levels increase, rather than decrease, reflecting net synthesis rather than net degradation or depletion.

There are three pathways reported to synthesize $\alpha$-keto$\beta$-methylvalerate and its product, isoleucine, through alternative routes of $\alpha$-ketobutyrate synthesis that do not involve threonine deamination. In arabidopsis, methionine- $\gamma$-lyase activity may produce $\alpha$-ketobutyrate from methionine (Joshi and Jander, 2009; Rebéillé et al., 2006). A second pathway has been found in yeast in which cystathionine- $\gamma$-lyase (Cys3) produces $\alpha$-ketobutyrate from cystathionine through cysteine biosynthesis (Ono et al., 1999). The third pathway for isoleucine biosynthesis has been described in Methanococcus jannaschii and Leptospira interrogans bacteria (Drevland et al., 2007; Howell et al., 1999; Westfall et al., 1983; Xu et al., 2004). In this pathway, acetyl-CoA and pyruvate are substrates for the formation of citramalic acid by citramalate synthase (CIM), which is a member of the IPMS family (Fig. 1). Citramalate, in turn, is then converted to $\alpha$-ketobutyrate. This "citramalate pathway" has not been conclusively demonstrated in plants and yeast, but data exist to support this possibility (Textor et al., 2007; Vollbrecht, 1974). Furthermore, detailed isotope labeling studies point to the possible existence of a novel pathway of fatty acid biosynthesis for sugar esters in members of the Solanaceae [e.g., tobacco (Nicotiana tabacum) and petunia (Petunia $\times$ hybrida)] led to the suggestion that some plants may possess CIM activity in specialized tissues (Kroumova and Wagner, 2003). Interestingly, Hulme (1954) isolated citramalic acid from the peel of the mature apple fruit. It was postulated that citramalic acid participated in the TCA cycle, although no data supported this suggestion. If the production of $\alpha$-keto- $\beta$-methylvalerate and its product, isoleucine, occurs through the citramalate synthase pathway or one of the other alternative pathways mentioned, it would explain the unique and unexpected accumulation of isoleucine during 'Jonagold' ripening. Isoleucine normally inhibits its own accumulation by feedback inhibition of TD (Mourad and King, 1995) and alternative routes of synthesis may not be similarly regulated.

In plants, TD activity is required for autotrophy in Nicotiana plumbaginifolia (Sidorov et al., 1981) and autotrophy was restored in an isoleucine-requiring Nicotiana TD mutant (ILE401) with a yeast TD gene (ILVI) in a complementation study (Colau et al., 1987). These data suggest that threonine degradation is the sole pathway for isoleucine biosynthesis in some plant tissues. Thus, Schaffer et al. (2007) suggested that TD contributes to the regulation of $\mathrm{BC}$ ester production by controlling threonine 
degradation and entry of carbon into the isoleucine synthetic pathway based on the upregulation of one of three TD ESTs (CN878598) in ripening apple. However, our TD expression data are not in accord with the findings by Schaffer et al. (2007), which would imply the converse of their interpretation, although realistically, little can be concluded regarding TD activity in vivo. The only related data from the current study are the difficult to reconcile increasing isoleucine content with the known feedback inhibition of TD by isoleucine. Inhibition of TD by isoleucine should yield accumulation of threonine (Mourad and King, 1995).

$P D C 1$ gene expression was low in preclimacteric fruit, increased during ripening, and remained elevated or increased slightly even during the latter stages of senescence. $P D C 1$ was the only one of the five PDC genes that had an expression pattern that, by virtue of its timing and degree, may be induced by the ripening process and associated with ester formation. However, the function of apple PDCs have not been characterized and a conclusive relationship to ester synthesis awaits further study. It is possible that one or more PDC may metabolize BC $\alpha$-keto acids. The idea that one or two PDC isozymes could have sufficient specificity to be primarily responsible for decarboxylation of $\mathrm{BC}$ $\alpha$-keto acids is supported by findings in yeast [Saccharomyces cerevisiae (Dickinson et al., 1997, 1998, 2000; Yoshimoto et al., 2001)]. Dickinson et al. (1997, 1998, 2000) concluded that a single PDC-like enzyme (a product of the gene YDLO80c) is likely responsible for leucine catabolism and two other isozymes of PDC are used for valine and isoleucine degradation.

Unfortunately, branched-chain $\alpha$-ketoacid decarboxylases (PDCs) are poorly studied in higher plants and little information is found characterizing PDC genes relative to ester formation. In fruit, PDC gene expression pattern was studied in developing grape berries (Or et al., 2000) and the crude extract of PDC activity was measured during maturation of strawberry and 'Fuji' apple (Echeverría et al., 2004; Moyano et al., 2004). The main purpose of these studies was to relate PDC activity and expression to ethanol production under anaerobic conditions or to the formation of ethanol-derived esters such as ethyl esters, not for BCAA metabolism. In the present study, the pattern of ethyl ester formation in 'Jonagold' appeared to reflect the pattern of only PDC1 expression, however, despite ethyl esters being found only at low levels (data not shown). The relatively high PDC1 expression in 'Jonagold' and the low ethyl ester production argue against a causative relationship between the expression of the gene and ethanol metabolism per se. The relevance of the changes in $P D C$ expression relative to the production of 2-methylbutyl and 2-methylbutanoate esters by 'Jonagold' apple fruit cannot be elaborated at this time and clarification of its role awaits characterization of the various apple PDC enzymes.

\section{Conclusion}

Collectively, the data support reassessing the perspective that the precursors for ester biosynthesis result from primarily degradative processes. In particular, the data surrounding isoleucine metabolism provide indications of enhanced synthetic activity. Importantly, the findings here may point to the existence of an alternative route of synthesis of $\alpha$-keto$\beta$-methylvalerate and its product, isoleucine. This possibility is supported by the large and sustained increase in isoleucine content despite declines in the concentrations of its amino acid precursors, the apparent lack of feedback inhibition to control the accumulation of isoleucine, and the lack of patterns in the expression of BCAT and TD genes that parallel isoleucine accumulation and $\mathrm{BC}$ ester formation. Furthermore, the presence of citramalate in apple and the potential for its contribution to the synthesis of $\alpha$-ketobutyrate formation provides a rationale supporting the existence of a citramalate-based pathway for the formation of $\alpha$-keto- $\beta$-methylvalerate and its product, isoleucine, that is not feedback-regulated similarly to that in bacteria. We propose that an alternative "citramalate pathway" exists in apple that bypasses threonine and permits the rapid and extensive accumulation of isoleucine through enhanced formation of $\alpha$-keto- $\beta$-methylvalerate. Given the coincidental timing of increased isoleucine formation with changes in internal ethylene and respiratory activity, it seems likely that if the citramalate pathway is active in apple fruit, it may be influenced by ethylene or is dependent on other developmental cues associated with ripening.

\section{Literature Cited}

Ackermann, J., M. Fischer, and R. Amado. 1992. Changes in sugars, acids, and amino acids during ripening and storage of apples (cv. Glockenapfel). J. Agr. Food Chem. 40:1131-1134.

Aharoni, A., L.C. Keizer, H.J. Bouwmeester, Z. Sun, M. AlvarezHuerta, H.A. Verhoeven, J. Blaas, A.M. van Houwelingen, R.C. De Vos, H. van der Voet, R.C. Jansen, M. Guis, J. Mol, R.W. Davis, M. Schena, A.J. van Tunen, and A.P. O'Connell. 2000. Identification of the SAAT gene involved in strawberry flavor biogenesis by use of DNA microarrays. Plant Cell 12:647-662.

Aharoni, A., C.H. Ric De Vos, H.A. Verhoeven, C.A. Maliepaard, G. Kruppa, R. Bino, and D.B. Goodenowe. 2002. Nontargeted metabolome analysis by use of Fourier transform ion cyclotron mass spectrometry. J. Integrative Biol. 6:217-234.

Azevedo, R.A., P. Arruda, W.L. Turner, and P.J. Lea. 1997. The biosynthesis and metabolism of the aspartate derived amino acids in higher plants. Phytochemistry 46:395-419.

Bartelt, R.J. 1997. Calibration of a commercial solid-phase microextraction device for measuring headspace concentrations of organic volatiles. Anal. Chem. 69:364-372.

Bartlem, D., I. Lambein, T. Okamoto, A. Itaya, Y. Uda, F. Kijima, Y. Tamaki, E. Nambara, and S. Naito. 2000. Mutation in the threonine synthase gene results in an over-accumulation of soluble methionine in arabidopsis. Plant Physiol. 123:101-110.

Beaudry, R., P. Schwallir, and M. Lennington. 1993. Apple maturity prediction: An extension tool to aid fruit storage decisions. HortTechnology 3:233-239.

Binder, S. 2010. Branched-chain amino acid metabolism in Arabidopsis thaliana. Arabidopsis Book 8:1-14.

Blanco Gomis, D., A.M. Picinelli Lobo, J. Mangas Alonso, and M.D. Gutierrez Alvarez. 1992. Determination of amino acids in ripening apples by high performance liquid chromatography. Zeitschrift für Lebensmittel-Untersuchung und -Forschung A 194:134-138.

Burroughs, L.F. 1957. The amino-acids of apple juices and ciders. J. Sci. Food Agr. 8:122-131.

Burroughs, L.F. 1970. Amino acids, p. 119-146. In: Hulme, A.C. (ed.). The biochemistry of fruits and their products Academic Press, London, UK/New York, NY.

Colau, D., I. Negrutiu, M. Van Montagu, and J.P. Hernalsteens. 1987. Complementation of a threonine dehydratase-deficient Nicotiana plumbaginifolia mutant after Agrobacterium tumefaciens-mediated transfer of the Saccharomyces cerevisiae ILV1 gene. Mol. Cell. Biol. 7:2552-2557.

Coruzzi, G.M. and R.L. Last. 2000. Amino acids, p. 358-410. In: Buchanan, R.B., W. Gruissem, and R. Jones (eds.). Biochemistry and molecular biology of plants. Amer. Soc. Plant Physiol. Press, Rockville, MD.

Defilippi, B.G., A.M. Dandekar, and A.A. Kader. 2005. Relationship of ethylene biosynthesis to volatile production, related enzymes, and 
precursor availability in apple peel and flesh tissues. J. Agr. Food Chem. 53:3133-3141.

Dickinson, J.R., S.J. Harrison, J.A. Dickinson, and M.J. Hewlins. 2000. An investigation of the metabolism of isoleucine to active amyl alcohol in Saccharomyces cerevisiae. J. Biol. Chem. 275:10937-10942.

Dickinson, J.R., S.J. Harrison, and M.J. Hewlins. 1998. An investigation of the metabolism of valine to isobutyl alcohol in Saccharomyces cerevisiae. J. Biol. Chem. 273:25751-25756.

Dickinson, J.R., M.M. Lanterman, D.J. Danner, B.M. Pearson, P. Sanz, S.J. Harrison, and M.J. Hewlins. 1997. A ${ }^{13} \mathrm{C}$ nuclear magnetic resonance investigation of the metabolism of leucine to isoamyl alcohol in Saccharomyces cerevisiae. J. Biol. Chem. 272:26871-26878.

Dixon, J. and E.W. Hewett. 2000. Factors affecting apple aroma/flavour volatile concentration: A review. N. Z. J. Crop Hort. Sci. 28:155-173. Drevland, R.M., A. Waheed, and D.E. Graham. 2007. Enzymology and evolution of the pyruvate pathway to 2-oxobutyrate in Methanocaldococcus jannaschii. J. Bacteriol. 189:4391-4400.

Echeverría, G., J. Graell, M.L. López, and I. Lara. 2004. Volatile production, quality and aroma-related enzyme activities during maturation of 'Fuji' apples. Postharvest Biol. Technol. 31:217-227.

Eisenstein, E. 1991. Cloning, expression, purification, and characterization of biosynthetic threonine deaminase from Escherichia coli. J. Biol. Chem. 266:5801-5807.

Fellman, J.K., D.S. Mattinson, B.C. Bostick, J.P. Mattheis, and M.E. Patterson. 1993. Ester biosynthesis in 'Rome' apples subjected to low-oxygen atmospheres. Postharvest Biol. Technol. 3:201-214.

Ferenczi, A. 2003. Patterns in the volatile profile for 'Redchief Delicious' apple fruit during ripening and senescence. MS thesis, Dept. of Horticulture, Michigan State Univ., East Lansing, MI.

Ferenczi, A., J. Song, M. Tian, K. Vlachonasios, D. Dilley, and R. Beaudry. 2006. Volatile ester suppression and recovery following 1-methylcyclopropene application to apple fruit. J. Amer. Soc. Hort. Sci. 131:691-701.

Frenkel, C., I. Klein, and D.R. Dilley. 1968. Protein synthesis in relation to ripening of pome fruits. Plant Physiol. 43:1146-1153.

Gonda, I., E. Bar, V. Portnoy, S. Lev, J. Burger, A.A. Schaffer, Y.a. Tadmor, S. Gepstein, J.J. Giovannoni, N. Katzir, and E. Lewinsohn. 2010. Branched-chain and aromatic amino acid catabolism into aroma volatiles in Cucumis melo L. fruit. J. Expt. Bot. 61:1111-1123.

Goto, M., I. Miyahara, H. Hayashi, H. Kagamiyama, and K. Hirotsu. 2003. Crystal structures of branched-chain amino acid aminotransferase complexed with glutamate and glutarate: True reaction intermediate and double substrate recognition of the enzyme. Biochemistry 42:3725-3733.

Gu, L., A.D. Jones, and R.L. Last. 2007. LC-MS/MS assay for protein amino acids and metabolically related compounds for large-scale screening of metabolic phenotypes. Anal. Chem. 79:8067-8075.

Hansen, E. 1970. Proteins, p. 147-158. In: Hulme, A.C. (ed.). The biochemistry of fruits and their products Academic Press, London, UK/New York, NY.

Howell, D.M., H. Xu, and R.H. White. 1999. (R)-Citramalate synthase in Methanogenic archaea. J. Bacteriol. 181:331-333.

Hulme, A.C. 1954. The isolation of L-citramalic acid from the peel of the apple fruit. Biochim. Biophys. Acta 14:36-43.

Joshi, V. and G. Jander. 2009. Arabidopsis methionine $\gamma$-lyase is regulated according to isoleucine biosynthesis needs but plays a subordinate role to threonine deaminase. Plant Physiol. 151:367-378.

Kakiuchi, N., S. Moriguchi, H. Fukuda, N. Ichimura, Y. Kato, and Y. Banba. 1986. Composition of volatile compounds of apple fruits in relation to cultivars. J. Jpn. Soc. Hort. Sci. 55:280-289.

Kroumova, A.B. and G.J. Wagner. 2003. Different elongation pathways in the biosynthesis of acyl groups of trichome exudate sugar esters from various solanaceous plants. Planta 216:1013-1021.

López-Gómez, R. and M.A. Gómez-Lim. 1992. A method for extracting intact RNA from fruits rich in polysaccharides using ripe mango mesocarp. HortScience 5:440-442.
Lo Scalzo, R., A. Testoni, and A. Genna. 2001. 'Annurca' apple fruit, a southern Italy apple cultivar: Textural properties and aroma composition. Food Chem. 73:333-343.

Lu, Y., L.J. Savage, I. Ajjawi, K.M. Imre, D.W. Yoder, C. Benning, D. Dellapenna, J.B. Ohlrogge, K.W. Osteryoung, A.P. Weber, C.G. Wilkerson, and R.L. Last. 2008. New connections across pathways and cellular processes: Industrialized mutant screening reveals novel associations between diverse phenotypes in arabidopsis. Plant Physiol. 146:1482-1500

Magné, C., M. Bonenfant-Magné, and J.-C. Audran. 1997. Nitrogenous Indicators of postharvest ripening and senescence in apple fruit (Malus domestica Borkh. cv. Granny Smith). Intl. J. Plant Sci. 158: 811-817.

Mattheis, J.P., D.A. Buchanan, and J.K. Fellman. 1991a. Change in apple fruit volatiles after storage in atmospheres inducing anaerobic metabolism. J. Agr. Food Chem. 39:1602-1605.

Mattheis, J.P., J.K. Fellman, P.M. Chen, and M.E. Patterson. 1991b. Changes in headspace volatiles during physiological development of Bisbee Delicious apple fruits. J. Agr. Food Chem. 39:1902-1906.

Mattheis, J.P., D.A. Buchanan, and J.K. Fellman. 1998. Volatile compounds emitted by 'Gala' apples following dynamic atmosphere storage. J. Amer. Soc. Hort. Sci. 123:426-432.

Mir, N.A., E. Curell, N. Khan, M. Whitaker, and R.M. Beaudry. 2001. Harvest maturity, storage temperature, and 1-MCP application frequency alter firmness retention and chlorophyll fluorescence of 'Redchief Delicious' apples. J. Amer. Soc. Hort. Sci. 126:618-624.

Mir, N.A., R. Perez, P. Schwallier, and R. Beaudry. 1999. Relationship between ethylene response manipulation and volatile production in Jonagold variety apples. J. Agr. Food Chem. 47:2653-2659.

Mourad, G. and J. King. 1995. L-O-Methylthreonine-resistant mutant of Arabidopsis defective in isoleucine feedback regulation. Plant Physiol. 107:43-52.

Moyano, E., S. Encinas-Villarejo, J.A. López-Ráez, J. RedondoNevado, R. Blanco-Portales, M.L. Bellido, C. Sanz, J.L. Caballero, and J. Muñoz-Blanco. 2004. Comparative study between two strawberry pyruvate decarboxylase genes along fruit development and ripening, post-harvest and stress conditions. Plant Sci. 166:835-845.

Nie, L.C., J.S. Sun, and B. Di. 2005. Changes in amino acid and fatty acid contents as well as activity of some related enzymes in apple fruit during aroma production. Zhi Wu Sheng Li Yu Fen Zi Sheng Wu Xue Xue Bao 31:663-667.

Olías, R., A.G. Pérez, and C. Sanz. 2002. Catalytic properties of alcohol acyltransferase in different strawberry species and cultivars. J. Agr. Food Chem. 50:4031-4036.

Ono, B.-I., T. Hazu, S. Yoshida, T. Kawato, S. Shinoda, J. Brzvwczy, and A. Paszewski. 1999. Cysteine biosynthesis in Saccharomyces cerevisiae: A new outlook on pathway and regulation. Yeast 15:1365-1375.

Or, E., J. Baybik, A. Sadka, and A. Ogrodovitch. 2000. Fermentative metabolism in grape berries: Isolation and characterization of pyruvate decarboxylase cDNA and analysis of its expression throughout berry development. Plant Sci. 156:151-158.

Ortiz, A., G. Echeverría, J. Graell, and I. Lara. 2010. The emission of flavour-contributing volatile esters by 'Golden Reinders' apples is improved after mid-term storage by postharvest calcium treatment. Postharvest Biol. Technol. 57:114-123.

Paillard, N.M.M. 1990. The flavour of apples, pears and quinces, p. 141. In: Morton, I.D. and A.J. Macleod (eds.). Food flavours, Part C. The flavour of fruits. Elsevier, Amsterdam, The Netherlands.

Park, S., N. Sugimoto, M.D. Larson, R. Beaudry, and S. van Nocker. 2006. Identification of genes with potential roles in apple fruit development and biochemistry through large-scale statistical analysis of expressed sequence tags. Plant Physiol. 141:811-824.

Pérez, A.G., R. Olías, P. Luaces, and C. Sanz. 2002. Biosynthesis of strawberry aroma compounds through amino acid metabolism. J. Agr. Food Chem. 50:4037-4042.

Plotto, A., M.R. McDaniel, and J.P. Mattheis. 2000. Characterization of changes in 'Gala' apple aroma during storage using osme analysis, 
a gas chromatography-olfactometry technique. J. Amer. Soc. Hort. Sci. 125:714-722.

Rebéillé, F., S. Jabrin, R. Bligny, K. Loizeau, B. Gambonnet, V. Van Wilder, R. Douce, and S. Ravanel. 2006. Methionine catabolism in Arabidopsis cells is initiated by a $\gamma$-cleavage process and leads to Smethylcysteine and isoleucine syntheses. Proc. Natl. Acad. Sci. USA 103:15687-15692.

Rowan, D.D., H.P. Lane, J.M. Allen, S. Fielder, and M.B. Hunt. 1996. Biosynthesis of 2-methylbutyl, 2-methyl-2-butenyl, and 2methylbutanoate esters in Red Delicious and Granny Smith apples using deuterium-labeled substrates. J. Agr. Food Chem. 44:32763285 .

Rowan, D.D., H.P. Lane, M.B. Hunt, and J.M. Allen. 1998. Metabolism of amino acids into aroma volatiles by five apple cultivars. Acta Hort. 464:490.

Rozen, S. and H. Skaletsky. 1999. Primer3 on the WWW for general users and for biologist programmers, p. 365-386. In: Misener, S. and S.A. Krawetz (eds.). Bioinformatics methods and protocols. Humana Press, Totowa, NJ.

Sanz, C., J.M. Olías, and A.G. Pérez. 1997. Aroma biochemistry of fruits and vegetables, p. 125-155. In: Tomás-Barberán, F.A. and R.J. Robins (eds.). Phytochemistry of fruit and vegetables. Oxford Univ. Press, New York, NY.

Schaffer, R.J., E.N. Friel, E.J. Souleyre, K. Bolitho, K. Thodey, S. Ledger, J.H. Bowen, J.H. Ma, B. Nain, D. Cohen, A.P. Gleave, R.N. Crowhurst, B.J. Janssen, J.L. Yao, and R.D. Newcomb. 2007. A genomics approach reveals that aroma production in apple is controlled by ethylene predominantly at the final step in each biosynthetic pathway. Plant Physiol. 144:1899-1912.

Schwallier, P., N. Mir, and R.M. Beaudry. 1995. Jonagold maturity and storage assessment. 128th Proc. Michigan State Hort. Soc. p. 205-215.

Sidorov, V., L. Menczel, and P. Maliga. 1981. Isoleucine-requiring Nicotiana plant deficient in threonine deaminase. Nature 294:87-88. Singh, B.K. and D.L. Shaner. 1995. Biosynthesis of branched chain amino acids: From test tube to field. Plant Cell 7:935-944.

Smit, B.A., W.J. Engels, J.T. Wouters, and G. Smit. 2004. Diversity of L-leucine catabolism in various microorganisms involved in dairy fermentations, and identification of the rate-controlling step in the formation of the potent flavour component 3-methylbutanal. Appl. Microbiol. Biotechnol. 64:396-402.

Song, J. and F. Bangerth. 1996. The effect of harvest date on aroma compound production from 'Golden Delicious' apple fruit and relationship to respiration and ethylene production. Postharvest Biol. Technol. 8:259-269.

Song, J., B. Gardener, J. Holland, and R. Beaudry. 1997. Rapid analysis of volatile flavor compounds in horticultural produce using SPME and GC/time-of-flight mass spectrometry. J. Agr. Food Chem. 45:1801-1807.

Souleyre, E.J.F., D.R. Greenwood, E.N. Friel, S. Karunairetnam, and R.D. Newcomb. 2005. An alcohol acyl transferase from apple (cv. Royal Gala), MpAAT1, produces esters involved in apple fruit flavor. FEBS J. 272:3132-3144.
Sugimoto, N. 2007. Volatile biosynthesis during ripening of 'Jonagold' apple fruit: Association of gene expression with aroma volatiles. MS thesis, Dept. of Horticulture, Michigan State Univ., East Lansing, MI. Tewari, Y.B., R.N. Goldberg, and J.D. Rozzell. 2000. Thermodynamics of reactions catalysed by branched-chain-amino-acid transaminase. J. Chem. Thermodyn. 32:1381-1398.

Textor, S., J.W. de Kraker, B. Hause, J. Gershenzon, and J.G. Tokuhisa. 2007. MAM3 catalyzes the formation of all aliphatic glucosinolate chain lengths in arabidopsis. Plant Physiol. 144:60-71.

Tressl, R. and F. Drawert. 1973. Biogenesis of banana volatiles. J. Agr. Food Chem. 21:560-565.

Ueda, Y. and K. Ogata. 1977. Coenzyme A-dependent esterification of alcohols and acids in separated cells of banana pulp and its homogenate. Nippon Shokuhin Kogyo Gakkaishi 24:624-630.

Ueda, Y., A. Tsuda, J.H. Bai, N. Fujishita, and K. Chachin. 1992. Characteristic pattern of aroma ester formation from banana, melon, and strawberry with reference to the substrate specificity of ester synthetase and alcohol contents in pulp. J. Jpn. Soc. Food Sci. Technol. 39:183-187.

Vollbrecht, D. 1974. Three pathways of isoleucine biosynthesis in mutant strains of Saccharomyces cerevisiae. Biochim. Biophys. Acta 362:382-389.

Wessel, P.M., E. Graciet, R. Douce, and R. Dumas. 2000. Evidence for two distinct effector-binding sites in threonine deaminase by sitedirected mutagenesis, kinetic, and binding experiments. Biochemistry 39:15136-15143.

Westfall, H.N., N.W. Charon, and D.E. Peterson. 1983. Multiple pathways for isoleucine biosynthesis in the spirochete Leptospira. J. Bacteriol. 154:846-853.

Wu, J., H. Gao, L. Zhao, X. Liao, F. Chen, Z. Wang, and X. Hu. 2007. Chemical compositional characterization of some apple cultivars. Food Chem. 103:88-93.

Wyllie, S.G. and J.K. Fellman. 2000. Formation of volatile branched chain esters in bananas (Musa sapientum L.). J. Agr. Food Chem. 48:3493-3496.

Wyllie, S.G., D.N. Leach, H.N. Nonhebel, and I. Lusunzi. 1996. Biochemical pathways for the formation of esters in ripening fruit, p. 52-57. In: Taylor, A.J. and D.S. Mottram (eds.). Flavour science, recent developments. Royal Soc. Chem., Cambridge, UK.

Xu, H., Y. Zhang, X. Guo, S. Ren, A.A. Staempfli, J. Chiao, W. Jiang, and G. Zhao. 2004. Isoleucine biosynthesis in Leptospira interrogans Serotype lai strain 56601 proceeds via a threonine-independent pathway. J. Bacteriol. 186:5400-5409.

Yahyaoui, F.E., C. Wongs-Aree, A. Latché, R. Hackett, D. Grierson, and J.C. Pech. 2002. Molecular and biochemical characteristics of a gene encoding an alcohol acyl-transferase involved in the generation of aroma volatile esters during melon ripening. Eur. J. Biochem. 269: 2359-2366.

Yoshimoto, H., T. Fukushige, T. Yonezawa, Y. Sakai, K. Okawa, A. Iwamatsu, H. Sone, and Y. Tamai. 2001. Pyruvate decarboxylase encoded by the PDC1 gene contributes, at least partially, to the decarboxylation of $\alpha$-ketoisocaproate for isoamyl alcohol formation in Saccharomyces cerevisiae. J. Biosci. Bioeng. 92:83-85. 